\title{
Evaluation of Incremental Improvements to Quantitative Precipitation Estimates in Complex Terrain
}

\author{
JONATHAN J. GOURLEY AND DAVID P. JORGENSEN \\ NOAA/National Severe Storms Laboratory, Norman, Oklahoma \\ SERGEY Y. MATROSOV \\ Cooperative Institute for Research in Environmental Sciences, University of Colorado, and NOAA/Earth System \\ Research Laboratory, Boulder, Colorado \\ ZACHARY L. FLAMIG \\ Cooperative Institute for Mesoscale Meteorological Studies, University of Oklahoma, Norman, Oklahoma
}

(Manuscript received 12 November 2008, in final form 10 June 2009)

\begin{abstract}
Advanced remote sensing and in situ observing systems employed during the Hydrometeorological Testbed experiment on the American River basin near Sacramento, California, provided a unique opportunity to evaluate correction procedures applied to gap-filling, experimental radar precipitation products in complex terrain. The evaluation highlighted improvements in hourly radar rainfall estimation due to optimizing the parameters in the reflectivity-to-rainfall $(Z-R)$ relation, correcting for the range dependence in estimating $R$ due to the vertical variability in $Z$ in snow and melting-layer regions, and improving low-altitude radar coverage by merging rainfall estimates from two research radars operating at different frequencies and polarization states. This evaluation revealed that although the rainfall product from research radars provided the smallest bias relative to gauge estimates, in terms of the root-mean-square error (with the bias removed) and Pearson correlation coefficient it did not outperform the product from a nearby operational radar that used optimized $Z-R$ relations and was corrected for range dependence. This result was attributed to better lowaltitude radar coverage with the operational radar over the upper part of the basin. In these regions, the data from the X-band research radar were not available and the C-band research radar was forced to use higherelevation angles as a result of nearby terrain and tree blockages, which yielded greater uncertainty in surface rainfall estimates. This study highlights the challenges in siting experimental radars in complex terrain. Last, the corrections developed for research radar products were adapted and applied to an operational radar, thus providing a simple transfer of research findings to operational rainfall products yielding significantly improved skill.
\end{abstract}

\section{Introduction}

The National Oceanic and Atmospheric Administration (NOAA) has set up a Hydrometeorological Testbed (HMT) Experiment on the North Fork of the American River basin (ARB) with an aim of improving hydrologic forecasts and flash-flood warnings through the use of advanced remote sensing and modeling technolo-

Corresponding author address: Jonathan J. Gourley, National Weather Center, 120 David L. Boren Blvd., Norman, OK 73072 7303.

E-mail: jj.gourley@noaa.gov gies. Data collected during the 2005/06 field phase of NOAA's HMT were used in this study to evaluate the hydrometeorological effects of 1) incremental improvements to radar-based quantitative precipitation estimates (QPEs) in complex terrain and 2) the added skill in QPE offered by research, gap-filling radars over operational radars, and the transferability of correction methods developed for research radars to operational radars.

Errors in radar-based QPE have been studied and quantified rigorously. Relevant literature reviews can be found in Wilson and Brandes (1979), Austin (1987), and Joss and Waldvogel (1990). Errors can be hardware specific, a function of the height of measurement, hydrometeor

DOI: 10.1175/2009JHM1125.1 
types, vertical air motions, and the assumed raindrop size spectrum in converting radar measurements to rainfall rates. Radar-specific errors can be caused by noise in the system hardware and miscalibration. Atlas (2002) provided a summary of radar calibration errors and simple approaches to correct them. For most practical applications, radar equivalent reflectivity $Z_{e}$ must be calibrated to within $1 \mathrm{~dB}$ to achieve rainfall estimates with errors $<15 \%$ (Ryzhkov et al. 2005). The vertical variability of reflectivity combined with radar beams increasing in altitude with range cause a range dependence of estimated rainfall rates. Kitchen and Jackson (1993) found that radars underestimate surface rainfall up to a factor of 10 at far range where beam overshooting is common. On the other hand, enhanced reflectivity associated with melting hydrometeors, or radar bright band (Austin and Bemis 1950), can cause significant overestimation (Smith 1986). Methods to correct for this range dependency often rely on a modeled or observed vertical profile of reflectivity (VPR; Joss and Waldvogel 1990; Kitchen et al. 1994; Andrieu and Creutin 1995; Joss and Lee 1995; Vignal et al. 1999; Seo et al. 2000; Germann and Joss 2002; Bellon et al. 2005). In addition to melting snow, the presence of hailstones can dramatically increase reflectivity and yield overestimated rainfall rates as a result of their differing dielectric factor
TABLE 1. Description of each IOP collected during HMT 2005/06 used in the analysis. The asterisk means that the data for this case did not cover the entire event as a result of a SR1 radar hardware failure.

\begin{tabular}{lccc}
\hline Event & $\begin{array}{c}\text { Start time } \\
\text { (UTC mm/dd/yy) }\end{array}$ & $\begin{array}{c}\text { End time } \\
\text { (UTC mm/dd/yy) }\end{array}$ & $\begin{array}{c}\text { Basin rainfall } \\
(\mathrm{mm})\end{array}$ \\
\hline IOP1 & $000012 / 01 / 05$ & $070012 / 02 / 05$ & 115.1 \\
IOP2 & $020012 / 18 / 05$ & $160012 / 19 / 05$ & 92.2 \\
IOP3 & $210012 / 20 / 05$ & $110012 / 22 / 05$ & 71.0 \\
IOP4 & $000012 / 31 / 05$ & $190012 / 31 / 05$ & $120.9 *$ \\
IOP5 & $190001 / 01 / 06$ & $230001 / 02 / 06$ & 49.5 \\
IOP6 & $050001 / 11 / 06$ & $190001 / 11 / 06$ & 13.5 \\
IOP7 & $120001 / 14 / 06$ & $020001 / 15 / 06$ & 38.5 \\
IOP10 & $130002 / 01 / 06$ & $190002 / 02 / 06$ & 54.7 \\
IOP11 & $130002 / 04 / 06$ & $190002 / 04 / 06$ & 15.5 \\
IOP12 & $230002 / 26 / 06$ & $100002 / 28 / 06$ & 125.6 \\
\hline
\end{tabular}

and large diameters (Austin 1987). Convective updrafts and downdrafts result in mass fluxes of hydrometeors that are different than their assumed fall velocities in still air (Battan 1976). Austin (1987) found the radar-measured $Z_{e}$ for a surface-observed $R$ in a convective downdraft to be $4-5 \mathrm{~dB}$ too low. Dotzek and Fehr (2003) employed a cloud-resolving model to illustrate and quantify the effect of convective drafts on surface-estimated rain rates as a function of storm life cycle. Lastly, a given relation to convert reflectivity to rainfall, the $Z-R$ relation, must

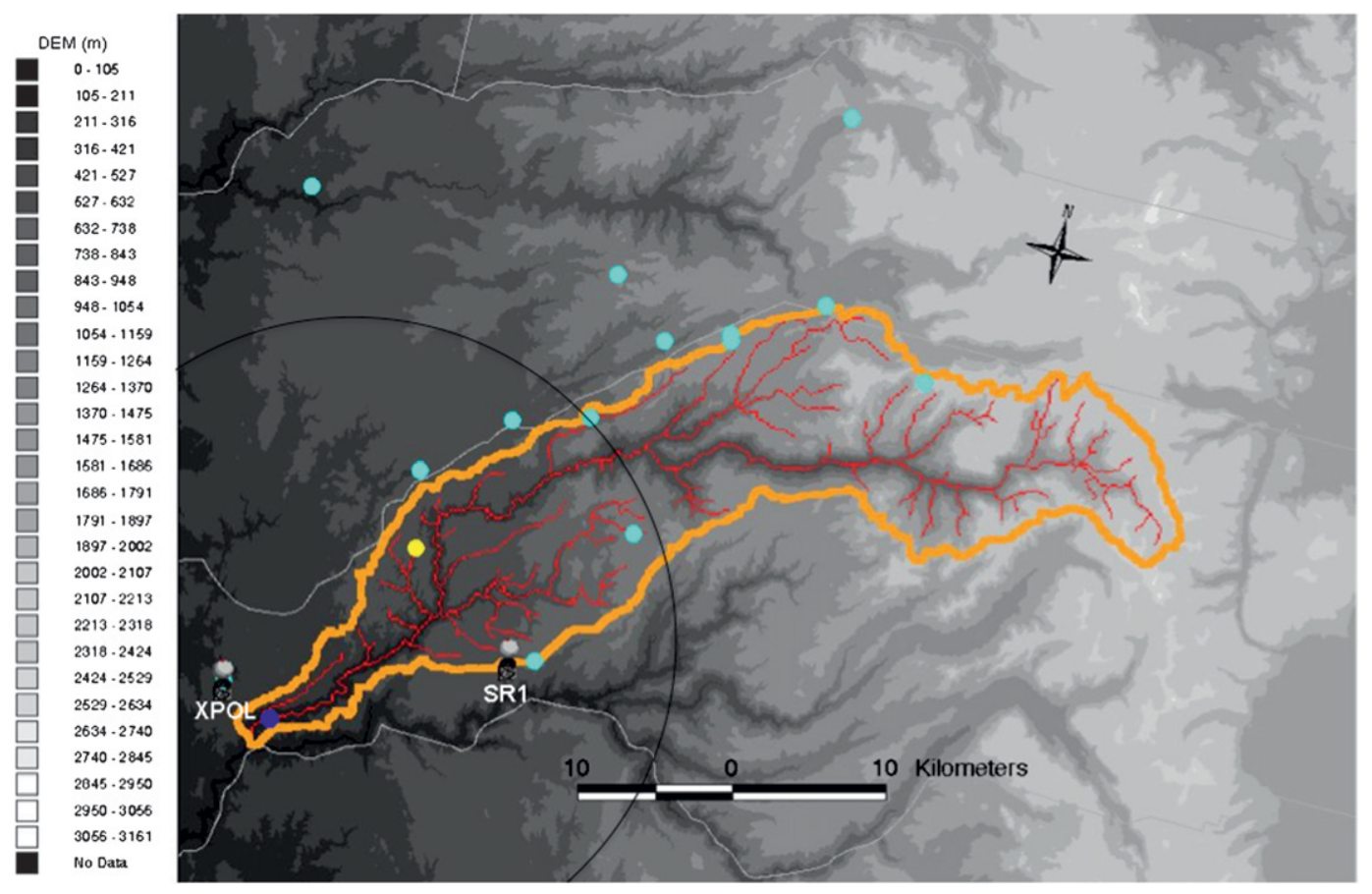

FIG. 1. DEM of the North Fork of the ARB (outlined in orange) in California. Cyan-filled circles show locations of ALERT and ESRL PSD gauges that were used to evaluate remotely sensed rainfall estimates. The yellow-filled circle shows the location of the Colfax disdrometer. Locations of the HYDROX (X-band) radar, its 38-km radius, and SR1 (C-band) research radar are also shown. 
TABLE 2. Summary of the iterative correction procedures applied to the research SR1 and the operational DAX radar data.

\begin{tabular}{lccccc}
\hline \hline & $Z$ calibration & $Z-R$ optimization & VPR correction & Rain-snow line & HYDROX merging \\
\hline SR1_0 & & & & & \\
SR1_1 & $\mathrm{X}$ & $\mathrm{X}$ & & & \\
SR1_12 & $\mathrm{X}$ & $\mathrm{X}$ & $\mathrm{X}$ & $\mathrm{X}$ & \\
SR1_123 & $\mathrm{X}$ & $\mathrm{X}$ & $\mathrm{X}$ & $\mathrm{X}$ & $\mathrm{X}$ \\
SR1_1234 & $\mathrm{X}$ & $\mathrm{X}$ & $\mathrm{X}$ & & \\
SR1_stitched & $\mathrm{X}$ & $\mathrm{X}$ & $\mathrm{X}$ & & \\
DAX_0 & & & & & \\
DAX_23 & & & & & \\
\hline
\end{tabular}

assume a distribution for the raindrop sizes. If the rain drop size distribution (DSD) deviates from the assumed DSD, then errors in rain rate estimates in light-to-moderate rain can exceed a factor of 2 (Austin 1987).

Evaluation of radar QPE products has traditionally been done using rain gauge accumulations at collocated radar-gauge bins. The attraction of this approach is its simplicity. The drawbacks are the lack of accuracy of rain gauge measurements, especially in high winds, and a point measurement may only represent the rainfall in close proximity to the gauge (Zawadzki 1975; Marselek 1981; Legates and DeLiberty 1993; Nystuen 1999; Ciach 2003). Moreover, the sampling sizes between a typical radar pixel and a rain gauge orifice differ by about eight orders of magnitude (Droegemeier et al. 2000). Regardless, radar-gauge comparisons are considered a standard and are completed in this study. Future work will evaluate the skill of incremental QPE improvements on hydrologic model simulations.

Section 2 discusses the physical characteristics of the study basin and the instrumentation relevant to this study that was employed during the 2005/06 field phase of HMT. Section 3 details the incremental corrections that were applied to the data collected by the research and operational radars. Comparisons of each QPE product to collocated rain gauge accumulations are shown in section 4 for each of the intensive operation periods. A summary of the skill of the QPE products based on rain gauge comparisons and conclusions are provided in section 5 .

\section{Study area and field instrumentation}

A climatology of precipitation in the ARB indicates the months of December and January are the wettest, whereas the summer months of July and August are the driest. During the month of December, $125 \mathrm{~mm}$ of rainfall on average falls in the lower parts of the ARB while $297 \mathrm{~mm}$ of liquid-equivalent precipitation falls in the upper reaches. Monthly climatologies indicate a mere $2 \mathrm{~mm}$ of rain falls in July. Mixed-phase precipitation events are common in the cool season as a result of an elevation increase of $2.5 \mathrm{~km}$, generally from west to east, over the ARB. Data collected during the cool season of 2005/06 were used in this study. A description of each event studied is summarized in Table 1 . The start and end times correspond to the times at which rain began to fall in the ARB and radar data collection commenced and when it ended. The fourth column in Table 1 is an accumulation of hourly, basin-averaged rain gauge analysis values. Details of the gauge analysis scheme are provided in section 3.

The HMT instrumentation relevant to this study includes 16 rain gauges, a disdrometer, the Sacramento weather surveillance radar [Weather Surveillance Radar1988 Doppler (WSR-88D)], and two research radars (Fig. 1). The county of Sacramento operates and maintains a network of Automated Local Evaluation in Real Time (ALERT) tipping-bucket rain gauges that report on a 15-min basis. These gauges are manufactured by a number of different vendors and thus their data quality

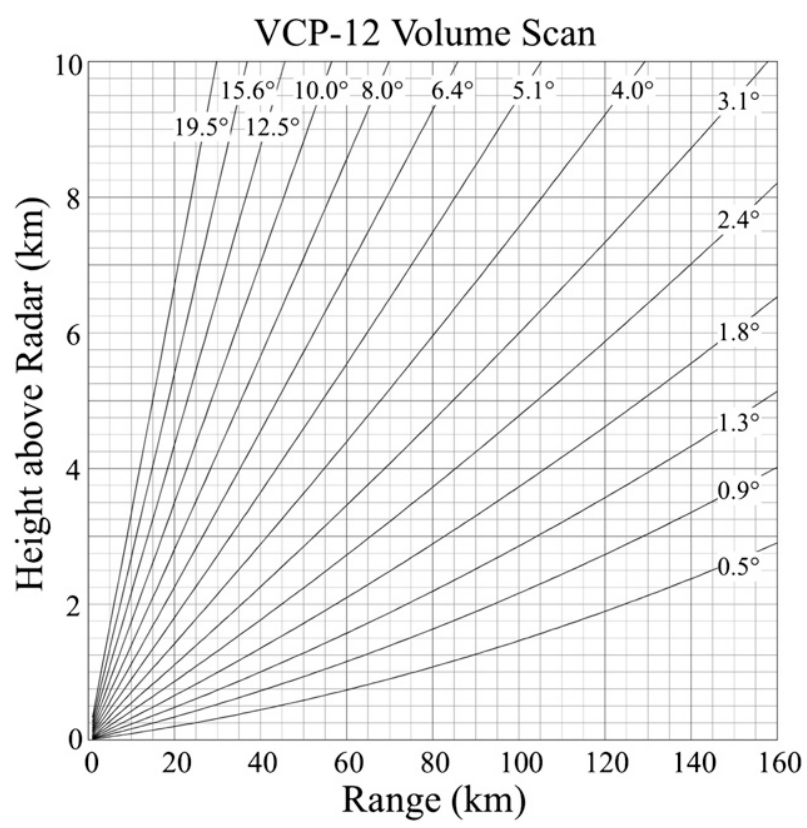

FIG. 2. VCP employed by NSSL's SR1 radar. An additional scan was performed at vertical incidence. 


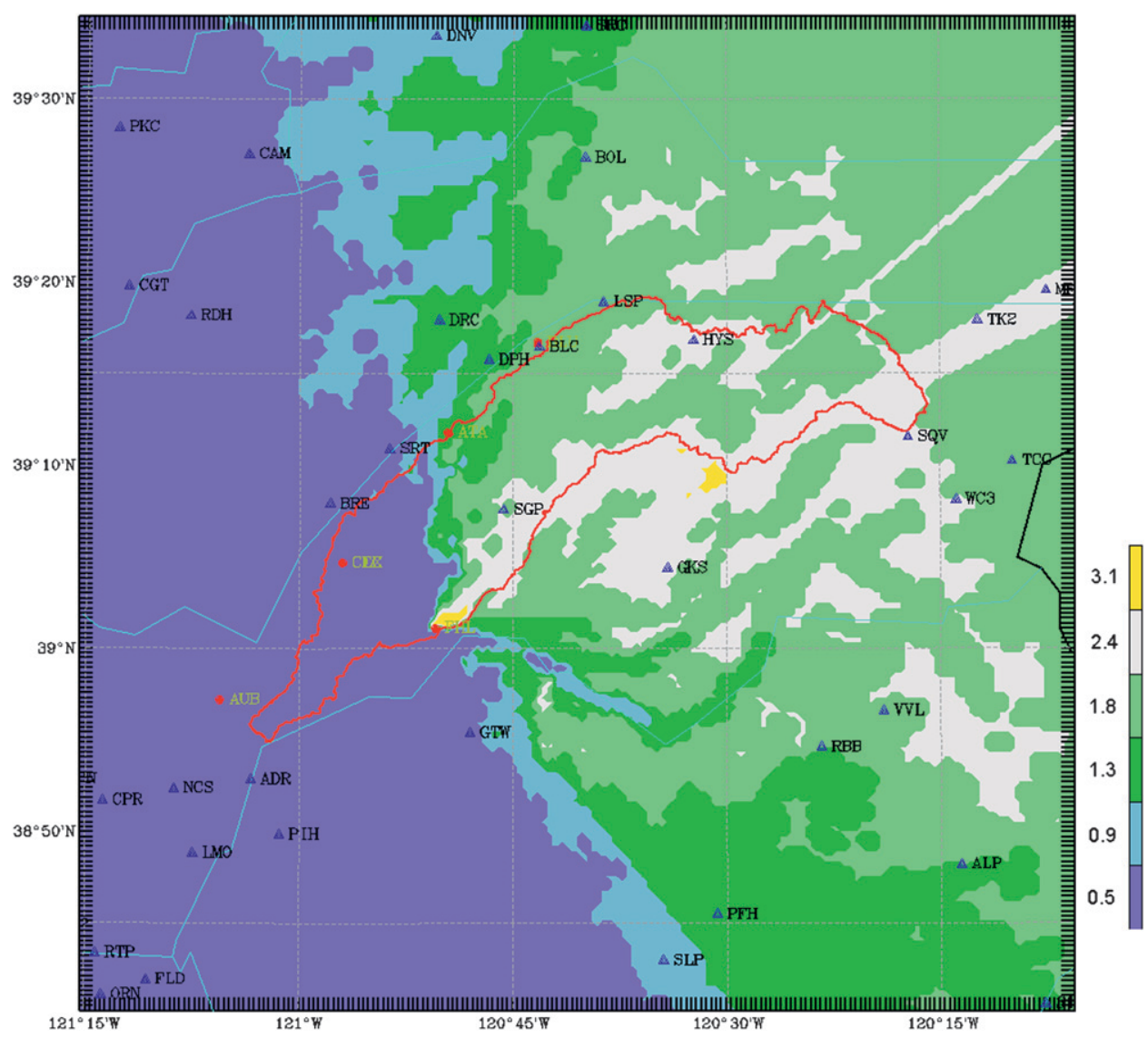

FIG. 3. Hybrid scan lookup table developed for SR1 reflectivity data. The colors correspond to radar elevation angles (in degrees) shown in the color bar. Entire network of ALERT rain gauges are shown as blue triangles and ESRL PSD gauges are shown as red circles.

must be carefully monitored. As part of the HMT experiment, NOAA's Earth System Research Laboratory's Physical Sciences Division (ESRL PSD) deployed nine observing platforms in the vicinity of the ARB, providing standard meteorological observations as well as 5-min precipitation totals. Figure 1 shows 10 ALERT gauges and five ESRL PSD gauges that were used to evaluate remotely sensed QPE fields in section 4. Three of the ESRL PSD gauges were manufactured by Met One Instruments, Inc. They were heated and wind shielded. The remaining two gauges, manufactured by Texas Electronics, were deployed in lower elevations and were neither heated nor wind shielded. All ESRL PSD gauges were factory calibrated to within $0.25 \mathrm{~mm}$. These gauges are a subset from the entire network; their selection was based on their close proximity to the ARB and the radar coverage provided by the research radars. A Distromet LTD model RD-80 disdrometer was used for radar calibration and for optimizing the $Z-R$ relation as described in section 3. The Sacramento WSR-88D radar (DAX) is $72 \mathrm{~km}$ away from the basin outlet and $147 \mathrm{~km}$ from the upper reaches of the ARB. Rainfall estimates derived from DAX reflectivity measurements were used in this study to compare with QPEs from the gap-filling, research radars. ESRL PSD deployed an X-band polarimetric radar (HYDROX) having a 3.1-m-diameter antenna, a peak transmit power of $30 \mathrm{~kW}$, beamwidth of $0.9^{\circ}$, gate spacing of $150 \mathrm{~m}$, and measurements out to a maximum range of $38.4 \mathrm{~km}$. Additional characteristics of HYDROX (formerly XPOL) are provided in Martner et al. (2001). The Shared Mobile Atmospheric Research and Teaching Radar (SR1) was deployed for HMT at Forest Hill by the National Severe Storms Laboratory (NSSL). SR1 is a C-band Doppler radar having a 2.4-m-diameter antenna with a maximum transmit power of $250 \mathrm{~kW}$ (Biggerstaff et al. 2005). It has a $1.5^{\circ}$ beam width, 125 -m nominal range gate spacing, and the maximum range was $150 \mathrm{~km}$.

\section{QPE processing}

A substantial amount of processing SR1 reflectivity measurements $\left(Z_{e}\right)$ was needed to yield QPEs with 


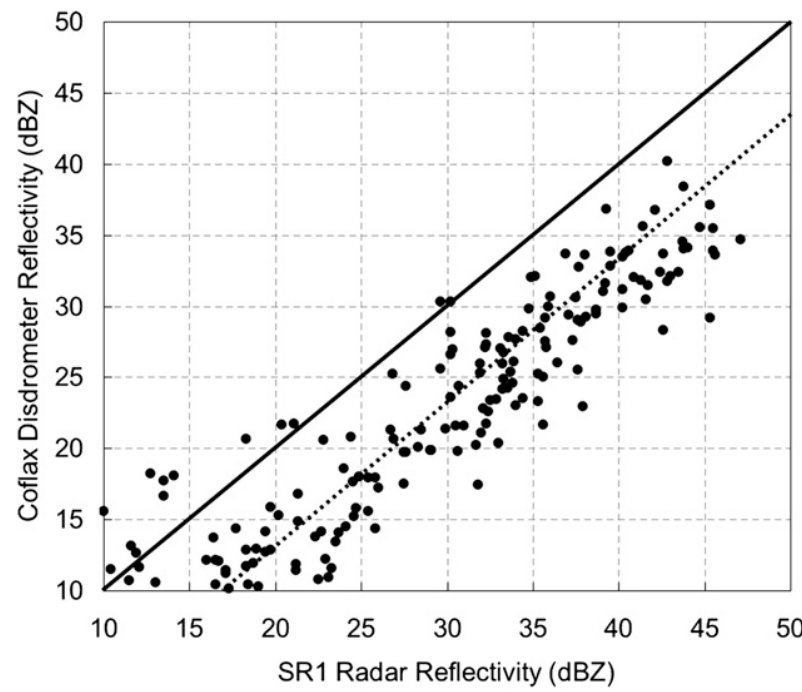

FIG. 4. Equivalent reflectivity from SR1 plotted against disdrometer reflectivity for IOP7. The mean offset for this IOP was $7.0 \mathrm{~dB}$, which is illustrated as the distance between the solid and dotted lines, whereas the offset for all IOPs combined was $6.8 \mathrm{~dB}$.

incremental corrections applied. The reader is referred to Table 2 to quickly see the number of corrections applied for each QPE product. SR1 collected raw measurements using volume coverage pattern (VCP) 12 with an added scan at vertical incidence (Fig. 2). An initial hybrid scan lookup table was computed based on modeled beam heights for VCP 12 relative to a 30-m-resolution digital elevation model (DEM). The intent of the hybrid scan was to reduce the three-dimensional volume scans to a two-dimensional reflectivity grid sampled closest to the ground. Manual analysis of hybrid scan reflectivity data revealed additional blockages that were unaccounted for in the DEM. These blockages were a result of trees and structures in close vicinity to the radar. The hybrid scan lookup table was thus edited to assign higher elevation angles to blocked radials. Figure 3 shows the $0.5^{\circ}$ elevation angle was used for the lower portion of the basin, whereas elevation angles as high as $3.1^{\circ}$ were needed to cover the entire basin. As will be seen in section 4, the siting of SR1 in complex terrain with nearby trees inhibited low-level coverage in the upper parts of the ARB. The HYDROX radar scanning procedure included sector scans at a $3^{\circ}$ elevation tilt with a maximum range of $38.4 \mathrm{~km}$, thus only $44 \%$ of the total North Fork of the ARB (in its lower part) was covered by this radar.

The first QPE product derived from SR1 data simply converted hybrid scan reflectivity to rainfall rate $(R)$ using the default $Z-R$ relation for the Next Generation Weather Radars (NEXRADs):

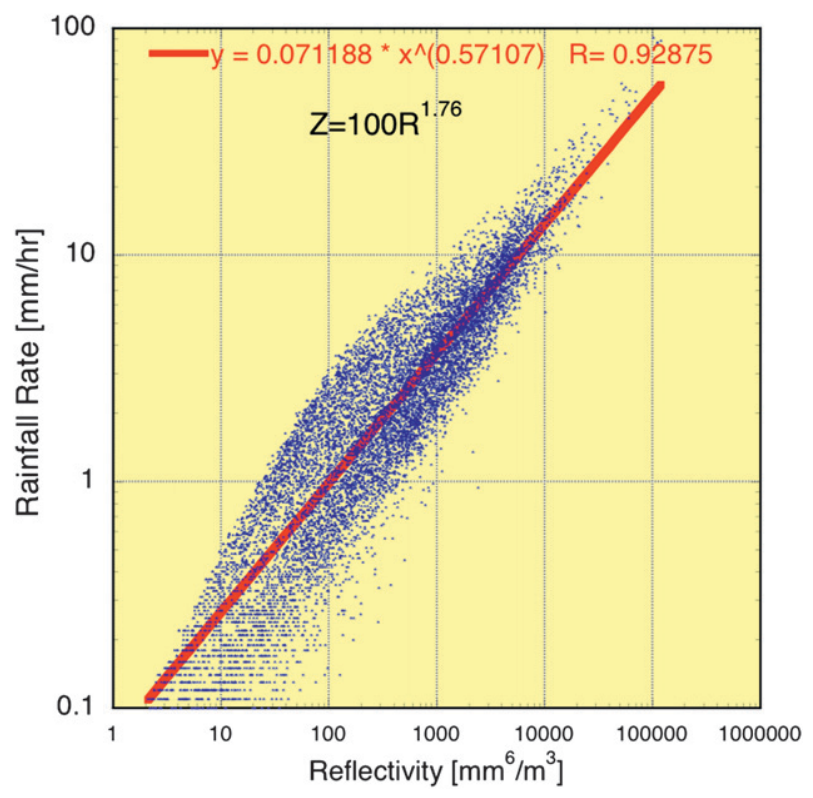

FIG. 5. Scatterplot of reflectivity and rainfall rate computed from the Colfax disdrometer for all IOPs listed in Table 1. Linear fit to the data is shown in red and optimized $Z-R$ relation is listed in black.

$$
Z=300 R^{1.4}
$$

where the units for $Z$ are $\mathrm{mm}^{6} \mathrm{~m}^{-3}$ and $R$ is $\mathrm{mm} \mathrm{h}^{-1}$. All radar-based QPE products were sampled from polar coordinates onto a 500-m-resolution Cartesian grid on an hourly basis. This QPE product was subjected to no corrections (hereafter SR1_0).

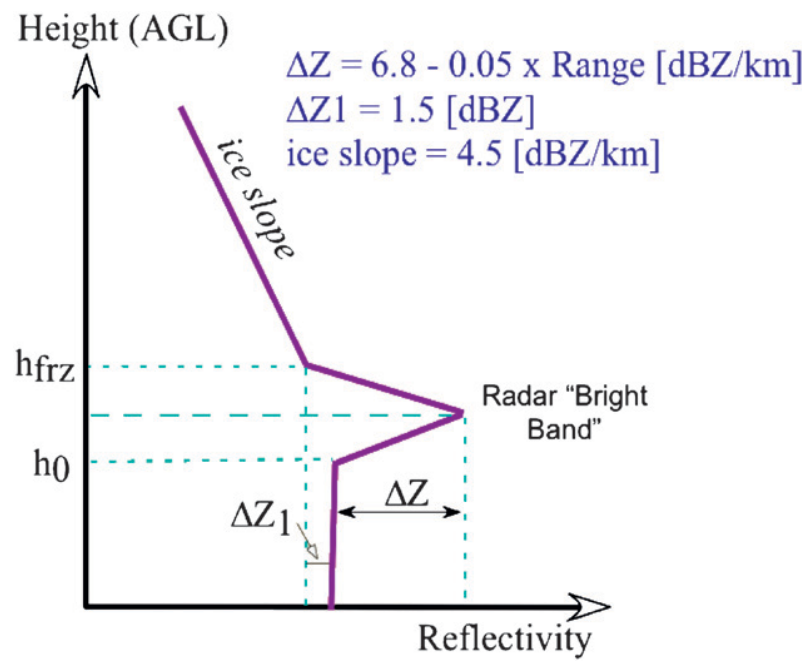

FIG. 6. Schematic of vertical profile of reflectivity model used to correct range biases in radar-based QPE from Matrosov et al. (2007). The $h_{\text {frz }}$ was either retrieved from HYDROX observations based on a reduction of the $\rho_{\mathrm{HV}}$ or based on RUC model analyses. The depth of the bright band $\left(h_{\mathrm{frz}}-h_{0}\right)$ was fixed at $900 \mathrm{~m}$. 

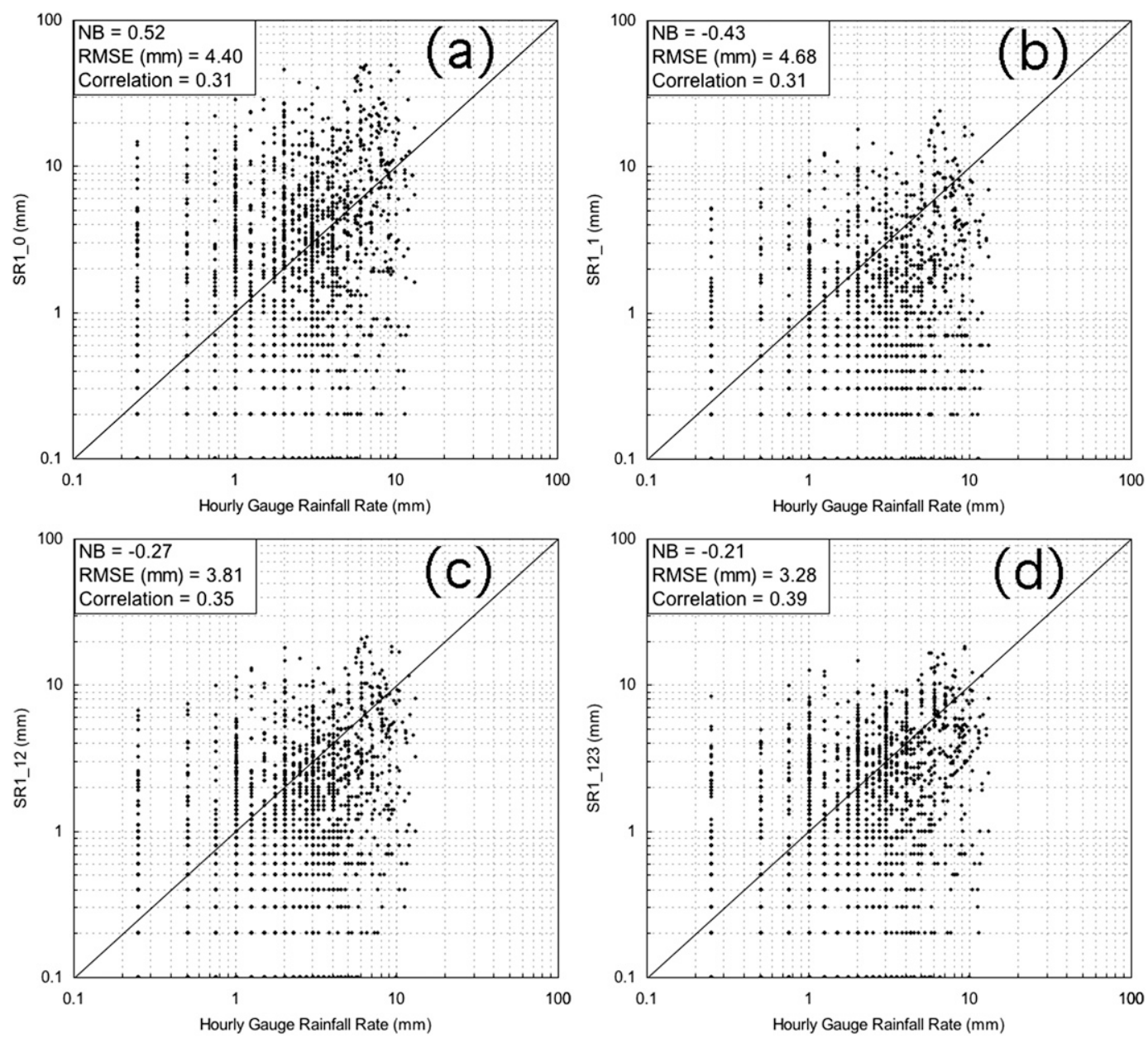

FIG. 7. Comparison of (a) SR1_0, (b) SR1_1, (c) SR1_12,(d)SR1_123, (e) SR1_1234, (f) SR1_stitched, (g) DAX_0, and (h) DAX_23 QPE products to hourly rain gauge accumulations for all IOPs listed in Table 1. Section 3 describes each QPE product.

The first incremental correction applied to SR1 data accounted for radar miscalibration using a disdrometer as in Joss et al. (1968). The SR1 radar was initially calibrated by injecting a signal into the receiver with known strength. This approach did not account for the combined calibration of the transmitter and receiver in weather signals. The Colfax disdrometer was located only $11.5 \mathrm{~km}$ away from SR1 (see Fig. 1). The close proximity of the disdrometer to SR1 meant errors due to horizontal advection and microphysical changes of hydrometeors below the altitude of radar sampling could be safely neglected. The disdrometer used an electromechanical transducer to measure each drop's momentum, which is proportional to drop diameter. The number density of drop diameters were then averaged on a 5-min basis and converted to reflectivity values to be comparable with radar-measured reflectivity values. For each intensive observing period (IOP), reflectivity computed from disdrometer data was compared to collocated reflectivity measurements from SR1 every five minutes. Figure 4 shows a scatterplot of disdrometer-toSR1 reflectivity data for IOP7. The mean offset of SR1 minus disdrometer reflectivity was $7.0 \mathrm{~dB}$ for this IOP, indicating SR1 reflectivity was biased extremely high. Similar plots were produced for each IOP and revealed that the mean offset for all IOPs was $6.8 \mathrm{~dB}$, with a standard deviation of $1.3 \mathrm{~dB}$. The stability of the calibration bias, despite its large absolute value, enabled us to use the mean offset value of $6.8 \mathrm{~dB}$ for all IOPs. The QPE product that has been corrected for radar miscalibration is hereafter referred to as SR1_1.

The second correction implemented on SR1 data considered deviations in the observed DSD from the assumed DSD used to convert reflectivity to rainfall rate using (1). Figure 5 shows a scatterplot of disdrometer-computed $Z$ and $R$ for all IOPs listed in Table 1 combined. Least 

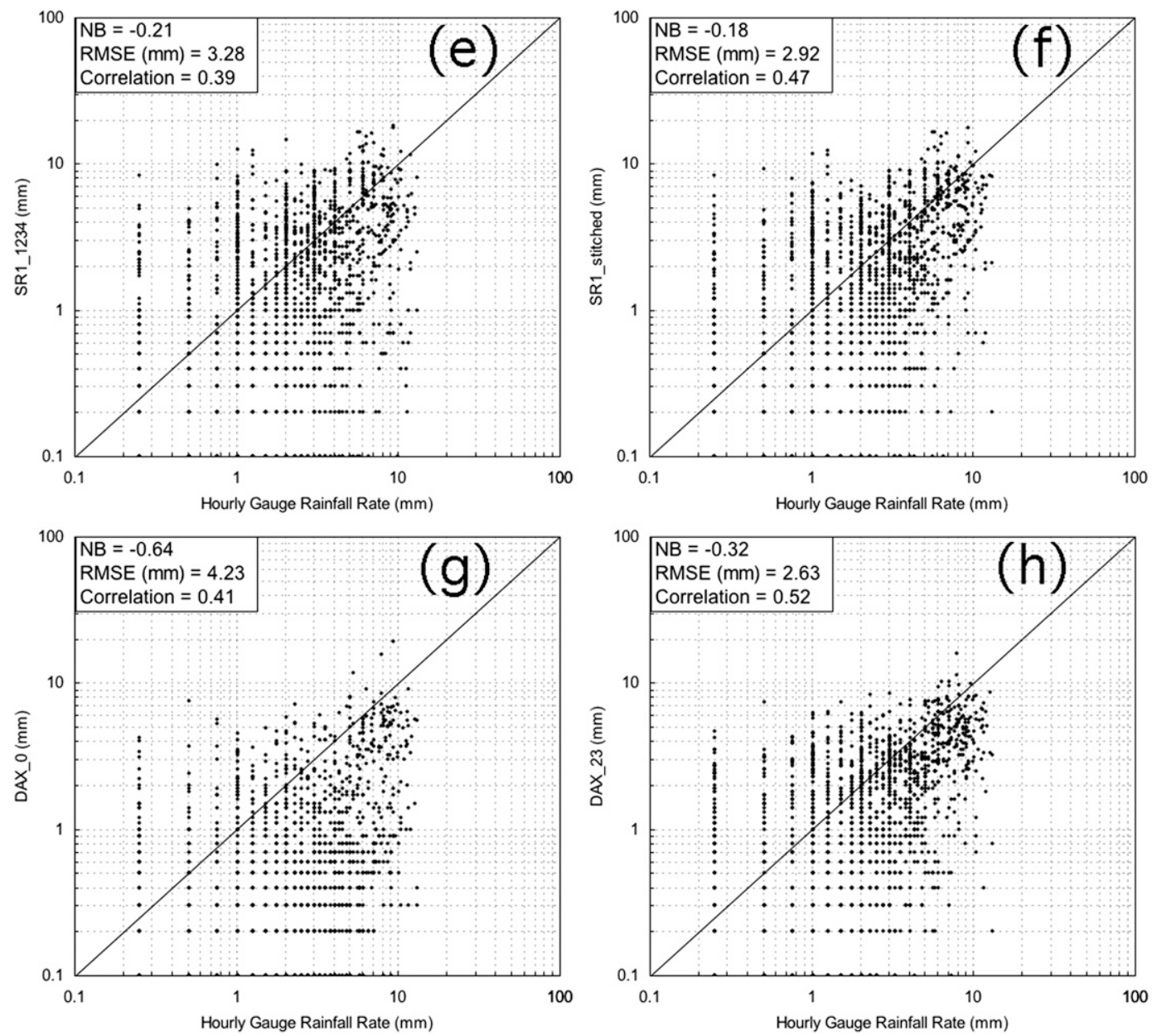

FIG. 7. (Continued)

squares regression was used to fit a line to the data that has the following form [with same units as Eq. (1)]:

$$
Z=100 R^{1.76} \text {. }
$$

It should be noted that the use of disdrometer-computed reflectivity to arrive at the provided formulation assumes radar-based reflectivity is compatible, or calibrated, which was done in the first step. Hypothetically speaking, the first correction to the radar calibration factor could have been superseded by directly comparing the uncalibrated SR $1 Z_{e}$ to the disdrometer-measured $R$. However, this would have made the $Z_{e}-R$ relation specific to the SR1 radar. As will be shown later in this section, a more general $Z-R$ relation found with disdrometer data in (2) was also applied to other radars, such as the operational DAX radar.

Although there may have been some variability in the $Z-R$ relation from event-to-event as reported in Matrosov et al. (2007), a Pearson correlation coefficient of 0.93 with a root-mean-square error (RMSE) of $1.8 \mathrm{~mm} \mathrm{hr}^{-1}$ was found for disdrometer-computed $R$ and $Z$ using data for all IOPs combined. The low DSD variability observed on the ARB may have been specific to synoptically forced orographic precipitation observed on the western slopes of the Sierra Nevada and thus may not be experienced in other precipitation regimes. The coefficient in (2) falls between the coefficients found for rainfall characterized by a presence of a brightband (BB) and nonbrightband (NBB) rainfall in Martner et al. (2008). Moreover, $R$ using (2) differs from rain rates computed for BB rainfall by less than $15 \%$ for $Z$ from $33-53 \mathrm{~dB} Z$; $Z$ must be $>46 \mathrm{~dB} Z$ to get agreement within $15 \%$ for $R$ computed for NBB rainfall. The low variance in our disdrometer-measured $R$ and agreement within $15 \%$ for $R$ computed for BB rainfall suggests a majority of observations during IOPs on the ARB was from rainfall with a melting-layer signature, with a small contribution from NBB rainfall. This assumption was verified by subjectively analyzing time series plots of signal-to-noise ratio as observed by an S-band profiling radar located at Alta, California, in the ARB (not shown). Martner et al. 
TABLE 3. Summary of the normalized bias computed for each IOP for each algorithm. Refer to Table 2 for the corrections that were made to each product. The algorithm with the best performance for each IOP according to the statistic is denoted in boldface.

\begin{tabular}{|c|c|c|c|c|c|c|c|c|c|c|}
\hline & IOP1 & IOP2 & IOP3 & IOP4 & IOP5 & IOP6 & IOP7 & IOP10 & IOP11 & IOP12 \\
\hline SR1_0 & 0.69 & 0.52 & 0.41 & 0.36 & 0.33 & -0.11 & 0.39 & 0.18 & -0.24 & 1.13 \\
\hline SR1_1 & -0.27 & -0.40 & -0.67 & -0.48 & -0.58 & -0.71 & -0.55 & -0.58 & -0.56 & -0.18 \\
\hline SR1_12 & -0.10 & -0.17 & -0.53 & -0.37 & -0.36 & -0.46 & -0.29 & -0.44 & -0.44 & -0.02 \\
\hline SR1_123 & -0.07 & -0.06 & -0.47 & -0.34 & -0.20 & -0.38 & 0.06 & -0.38 & -0.40 & -0.08 \\
\hline SR1_1234 & -0.07 & -0.06 & -0.47 & -0.34 & -0.20 & -0.38 & 0.06 & -0.38 & -0.40 & -0.08 \\
\hline SR1_stitched & -0.02 & -0.08 & -0.41 & -0.26 & -0.07 & -0.38 & 0.04 & -0.30 & -0.31 & -0.16 \\
\hline DAX_0 & -0.70 & -0.71 & -0.47 & -0.53 & -0.70 & -0.82 & -0.75 & -0.73 & -0.88 & -0.59 \\
\hline DAX_23 & -0.31 & -0.29 & -0.22 & -0.34 & -0.26 & -0.49 & -0.10 & -0.49 & -0.72 & -0.30 \\
\hline
\end{tabular}

(2008) found melting-layer signatures to be present with ice processes in deep clouds associated with synopticscale forcing. This is consistent with the IOP planning procedure that focused on events for study during strong synoptic forcing. The QPE product that has been corrected for radar miscalibration and used (2) for rain-rate estimation is hereafter referred to as SR1_12. SR1 QPE products hereafter relied on (2) for rain-rate estimation.

The next correction was designed to resolve range biases in QPE caused by the vertical variability of reflectivity using the method described in Matrosov et al. (2007). Figure 6 shows a modeled vertical profile of reflectivity that has been parameterized to describe orographically generated stratiform precipitation with a melting-layer signature, or bright band. All parameters listed in blue were manually adjusted based on HYDROX-observed reflectivity profiles for IOP7 as well as a comparison to collocated rain gauge accumulations. Although presented values of $\Delta Z$ and $\Delta Z_{1}$, which were used in this study, are averages, one can expect that they may change depending on conditions. For example, $\Delta Z_{1}$ could increase with decreasing radar elevation angle because longer path lengths in the melting layer would add more melting-layer attenuation, which is generally more significant than attenuation in rain (Matrosov 2008). The only parameter that was adjusted in this study is the freezing-level height $\left(h_{\text {frz }}\right)$. These values were retrieved either from HYDROX observations based on a reduction of the co-polar cross-correlation coefficient $\left(\rho_{\mathrm{HV}}\right)$ or
Rapid Update Cycle (RUC) model analyses. HYDROX $\rho_{\mathrm{HV}}$ observations were used during the times at which low-level scans intercepted the melting layer; otherwise, values were taken directly from the RUC model on an hourly basis. Provided the height of the radar measurement, the model shown in Fig. 6 was used to extrapolate measured reflectivity to represent values at the surface. It should be noted that improvements are expected when SR1 is upgraded with polarimetric diversity and can thus use a line of sight $\rho_{\mathrm{HV}}$ as opposed to using the measurements from HYDROX. Reflectivity values were then corrected for radar miscalibration and converted to rainfall rates using (2). This product is hereafter referred to as SR1_123.

Analysis of the aforementioned freezing-level height time series indicated mixed-phase precipitation affected the ARB for all IOPs except IOP3. IOP7 was the coldest event with freezing-level heights falling to $1.42-\mathrm{km} \mathrm{MSL}$. In this study, grid points receiving frozen precipitation were identified by comparing terrain heights from the DEM (see Fig. 1) to freezing-level heights on an hourly basis. If the DEM height was greater than the freezinglevel height, then rain rates at those grid points were simply set to zero. The rain-snow product, referred to hereafter as SR1_1234, had the same values as SR1_123 but with rainfall rates set to zero at grid points above the freezing layer.

The final correction to SR1 data merged rainfall rate estimates from HYDROX with SR1. Reflectivity data

TABLE 4. Same as Table 3 but for RMSE.

\begin{tabular}{|c|c|c|c|c|c|c|c|c|c|c|}
\hline & IOP1 & IOP2 & IOP3 & IOP4 & IOP5 & IOP6 & IOP7 & IOP10 & IOP11 & IOP12 \\
\hline SR1_0 & 6.01 & 3.95 & 3.25 & 7.35 & 2.68 & 1.02 & 2.21 & 2.56 & 3.31 & 5.18 \\
\hline SR1_1 & 7.24 & 4.12 & 3.09 & 7.40 & 2.40 & 1.18 & 2.04 & 2.23 & 3.68 & 5.30 \\
\hline SR1_12 & 5.44 & 3.45 & 2.82 & 6.12 & 2.31 & 0.92 & 1.97 & 2.14 & 2.76 & 4.44 \\
\hline SR1_123 & 4.18 & 2.62 & 2.99 & 5.40 & 2.13 & 0.96 & 2.74 & 2.27 & 3.34 & 3.54 \\
\hline SR1_1234 & 4.18 & 2.62 & 2.99 & 5.40 & 2.13 & 0.96 & 2.74 & 2.27 & 3.34 & 3.54 \\
\hline SR1_stitched & 3.88 & 2.42 & 3.03 & 4.09 & 2.05 & 1.04 & 2.44 & 2.33 & 3.52 & 3.03 \\
\hline DAX_0 & 3.68 & 3.45 & 4.08 & 8.30 & 2.91 & 1.08 & 2.33 & 2.42 & 3.63 & 4.35 \\
\hline DAX_23 & 2.49 & 2.56 & 2.89 & 3.96 & 1.95 & 1.12 & 2.11 & 1.94 & 2.99 & 3.01 \\
\hline
\end{tabular}


TABLE 5. Same as Table 3 but for Pearson correlation coefficient.

\begin{tabular}{|c|c|c|c|c|c|c|c|c|c|c|}
\hline & IOP1 & IOP2 & IOP3 & IOP4 & IOP5 & IOP6 & IOP7 & IOP10 & IOP11 & IOP12 \\
\hline SR1_0 & 0.36 & 0.14 & 0.23 & 0.04 & 0.01 & 0.29 & 0.15 & -0.05 & -0.06 & 0.02 \\
\hline SR1_1 & 0.34 & 0.12 & 0.18 & 0.05 & -0.02 & 0.28 & 0.11 & -0.05 & -0.08 & -0.02 \\
\hline SR1_12 & 0.40 & 0.18 & 0.24 & 0.06 & 0.04 & 0.31 & 0.17 & -0.01 & -0.03 & 0.04 \\
\hline SR1_123 & 0.45 & 0.28 & 0.18 & 0.05 & 0.24 & 0.33 & 0.12 & -0.04 & -0.03 & 0.16 \\
\hline SR1_1234 & 0.45 & 0.28 & 0.18 & 0.05 & 0.24 & 0.33 & 0.12 & -0.04 & -0.03 & 0.16 \\
\hline SR1_stitched & 0.47 & 0.31 & 0.19 & 0.24 & 0.23 & 0.29 & 0.12 & -0.07 & 0.00 & 0.18 \\
\hline DAX & 0.41 & 0.19 & 0.27 & 0.20 & -0.11 & 0.34 & 0.12 & -0.14 & -0.19 & -0.14 \\
\hline DAX_23 & 0.59 & 0.30 & 0.28 & 0.18 & 0.18 & 0.20 & 0.22 & -0.07 & 0.01 & 0.11 \\
\hline
\end{tabular}

from HYDROX were initially corrected for miscalibration using a corner reflector and then through reflectivity comparisons observed by the Colfax disdrometer once the radar was deployed in the field. Reflectivity data were then corrected for attenuation losses using the polarimetric method outlined in Matrosov et al. (2005), and range effects were mitigated using the vertical profile of the reflectivity model shown in Fig. 6 (Matrosov et al. 2007). Rainfall rates were estimated using the same $Z-R$ relation shown in (2). Consideration of frozen hydrometeors accumulating at the surface was not warranted with HYDROX data as a result of its low-elevation siting at 468-m MSL and production of rainfall rates out to a maximum range of $38 \mathrm{~km}$. The merging technique simply replaced SR1_1234 rain rates with HYDROX rain rates at grid points where HYDROX data were available. This product is hereafter referred to as SR1_stitched (see Table 2 for a summary).

Rainfall estimates with two levels of correction were produced using reflectivity measurements from the operational NEXRAD in Sacramento called DAX. The first product, hereafter referred to as DAX_0, was similar to SR1_0 in that it is considered raw with no corrections and relied on the default $Z-R$ relation shown in (1). In essence, the DAX_0 product approximates the operational rainfall algorithm. Comparisons of DAX reflectivity to disdrometer observations, which would be needed for calibration, were problematic because of the distance of $91 \mathrm{~km}$ between the two instruments. It is thus assumed that the operational DAX radar was reasonably calibrated. Reflectivity comparisons from neighboring NEXRADs were examined and showed no significant biases (not shown). The second product used the optimized $Z-R$ relation shown in (2) and corrected for range effects using the model illustrated in Fig. 6. In this case, the freezing-level heights were used exclusively from RUC model analyses. This product, hereafter referred to as DAX_23, represents a QPE product derived from the operational radar network with corrections applied that do not rely on experimental observations in the future but rather data available in an operational setting.

A QPE product based on the 10 ALERT and five ESRL PSD gauge reports shown in Fig. 1, referred to as GAG_0, was analyzed for subjective comparison with radar-based products. First, raw gauge reports were quality controlled through manual, meticulous inspection of each station's time series file covering each IOP. Then, the 5- and 15-min gauge reports were aggregated up to hourly accumulations, available at the top of each hour. The gauge data were then sampled onto the 500-mresolution Cartesian grid using natural neighbor linear interpolation (Akima 1978; Sibson 1981). The method calculated area-based weights and produced an interpolated surface with continuous slope except at the gauge locations where the quality-controlled gauge value was used. The result of this interpolation scheme was a smooth surface with sharp gradients, analogous to tent poles, at

TABLE 6. Same as Table 3 but for number of nonzero radar-gauge pairs.

\begin{tabular}{|c|c|c|c|c|c|c|c|c|c|c|}
\hline & IOP1 & IOP2 & IOP3 & IOP4 & IOP5 & IOP6 & IOP7 & IOP10 & IOP11 & IOP12 \\
\hline SR1_0 & 162 & 218 & 138 & 144 & 151 & 71 & 123 & 174 & 36 & 244 \\
\hline SR1_1 & 156 & 210 & 122 & 143 & 137 & 71 & 116 & 146 & 32 & 226 \\
\hline SR1_12 & 165 & 219 & 137 & 144 & 152 & 71 & 124 & 185 & 38 & 245 \\
\hline SR1_123 & 165 & 220 & 137 & 143 & 152 & 71 & 121 & 181 & 38 & 245 \\
\hline SR1_1234 & 165 & 220 & 137 & 143 & 152 & 71 & 121 & 181 & 38 & 245 \\
\hline SR1_stitched & 162 & 212 & 136 & 147 & 155 & 69 & 124 & 181 & 37 & 249 \\
\hline DAX_0 & 158 & 200 & 74 & 148 & 155 & 54 & 117 & 154 & 24 & 243 \\
\hline DAX_23 & 165 & 218 & 79 & 148 & 173 & 71 & 125 & 187 & 38 & 251 \\
\hline
\end{tabular}



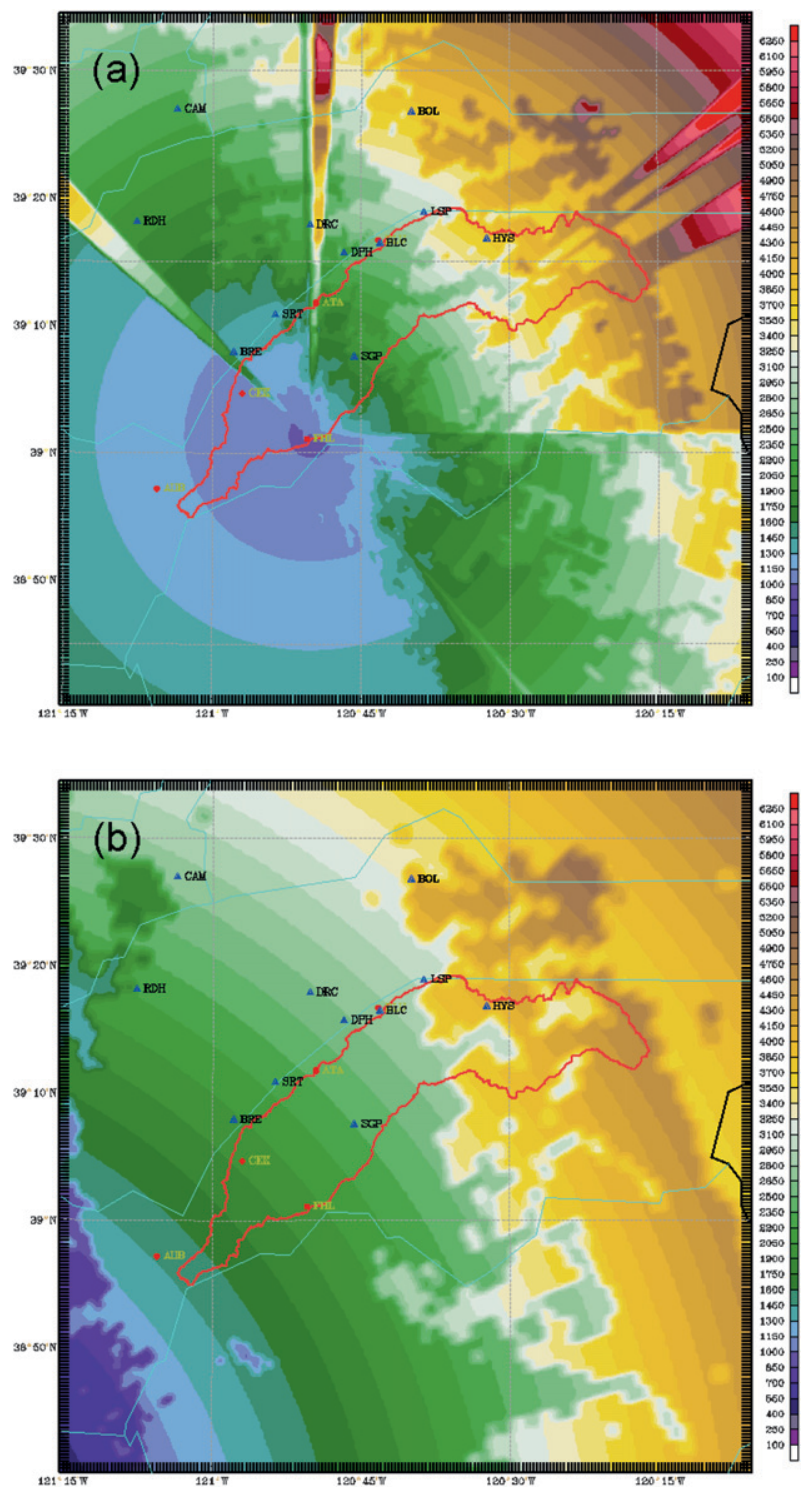

FIG. 8. Height of the hybrid scan beam heights (in $\mathrm{m}$ above MSL) for (a) SR1 and (b) DAX. The ALERT and ESRL PSD gauges used in the rain gauge evaluation are shown as blue triangles and red circles, respectively. The ARB is outlined in red.

the gauge locations. The GAG_0 served as a benchmark for subjective comparison purposes with the remotely sensed, radar-based QPE products.

\section{Results}

The evaluation compared radar-based QPEs from the research radars and the operational DAX radar to rain gauge accumulations. QPEs from SR1, subject to incremental corrections, and from uncorrected and corrected DAX were plotted against hourly rain gauge

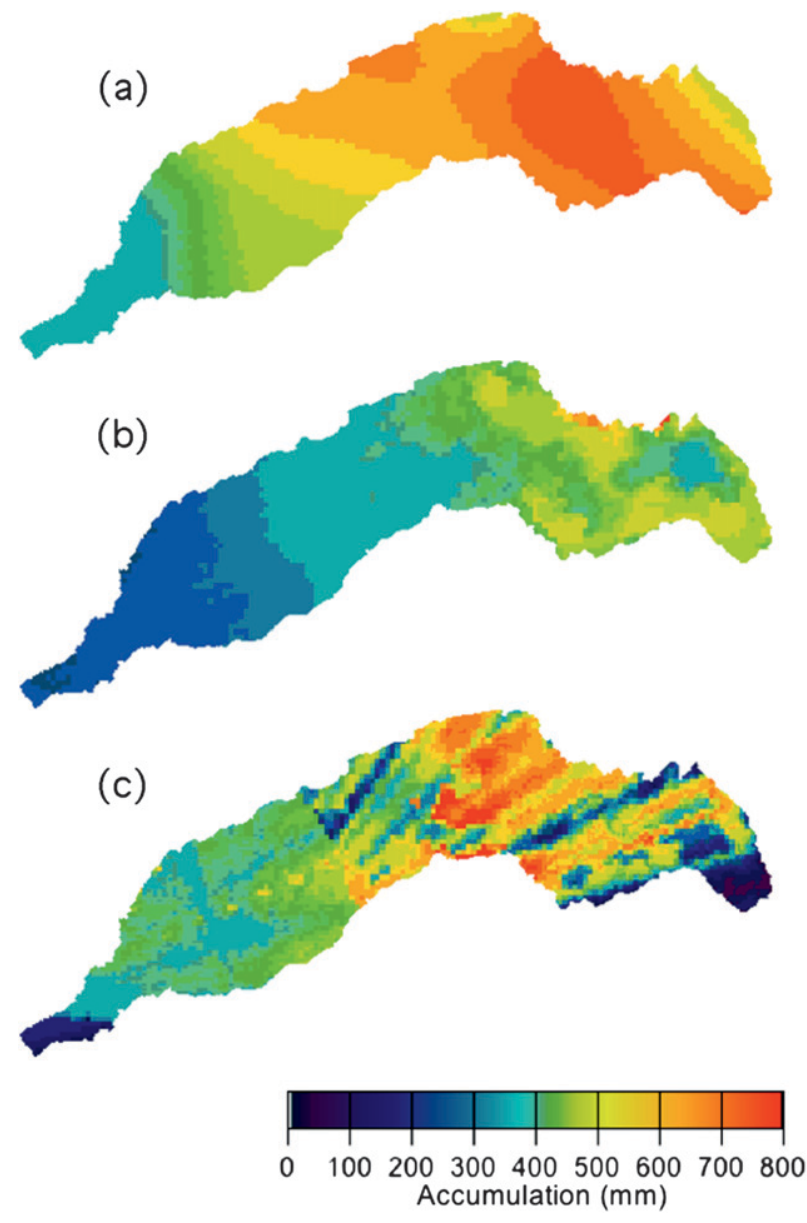

FIG. 9. Rainfall accumulation on the North Fork of the ARB for all IOPs combined from (a) GAG_0, (b) DAX_23, and (c) SR1_stitched. Refer to section 3 for detailed descriptions of each rainfall product.

accumulations on a log scale at collocated grid points for all IOPs combined (see Fig. 7). Radar-gauge pairs were considered if both reports were nonzero. Each panel in Fig. 7 indicates the normalized bias (NB; defined as the sum of radar minus gauge accumulations divided by the sum of the gauge accumulations), RMSE computed after the radar bias was removed, and Pearson correlation coefficient. The highest skill in a given QPE product is indicated with a normalized bias nearest 0.0 (in which negative numbers indicate underestimation and positive numbers indicate overestimation), lowest RMSE, and highest correlation coefficient. In addition, we computed the aforementioned skill metrics for each IOP separately and reported those in Tables 3-6.

The SR1_0 product showed very little skill when compared to rain gauge accumulations (Fig. 7a). Significant overestimation occurred because of the extreme 6.8-dB miscalibration of the radar. When considering all 
gauges for all IOPs, overestimation with a NB of 0.52 , or $52 \%$, occurred with SR1_0. When the radar was properly calibrated, as was the case with the SR1_1 product, the correlation coefficient remained unchanged, the RMSE increased, and the NB became -0.43 , indicating underestimation by $43 \%$. Evidently, radar calibration alone did not provide substantial improvements in skill to QPE algorithms when an improper $Z-R$ relation was used. Optimizing the parameters in the $Z-R$ relation in the SR1_12 product, which required calibrated radar reflectivity data, resulted in substantial improvements in all three scores. Further improvement in all scores was gained in the SR1_123 product by implementing a range correction procedure based on the modeled vertical profile of reflectivity. These improvements were not entirely unexpected; we optimized the ice slope parameter illustrated in Fig. 6 using rain gauge comparisons for IOP7. Evidently, the optimization was appropriate for the other IOPs. The skill scores remained virtually unchanged when consideration of the rain/snow line was made in the SR1_1234 product. This was because the rain gauges used in the analysis (see Fig. 1) were situated at altitudes below the freezing level for most IOPs. Thus, the SR1_1234 product was the same as the SR1_123 product in the raining regions. The final correction to SR1 data, stitching together the SR1_1234 product with HYDROX rain rates, resulted in modest improvements in all three skill scores. The best scores we achieved after applying all incremental corrections to reflectivity data from merged, gap-filling radars were an NB of -0.18 , an RMSE of $2.92 \mathrm{~mm}$, and Pearson correlation coefficient of 0.47 .

The uncorrected DAX QPE product, DAX_0, substantially underestimated gauge amounts, as noted with an NB of -0.64 (Fig. $7 \mathrm{~g}$ ). The RMSE was lower than with SR1_0 and SR1_1, and the correlation coefficient was unexpectedly higher than all SR1 QPE products, except SR1_stitched, with a value of 0.41 . The application of the optimized $Z-R$ relation and vertical reflectivity correction improved the NB of DAX_23 to -0.32 and yielded the lowest RMSE $(2.63 \mathrm{~mm})$ and highest correlation coefficient (0.52) of all radar-based QPE products.

The unexpectedly high skill of DAX_23 relative to the merged, gap-filling SR1_stitched product prompted us to examine radar coverages over the ARB. A study by Maddox et al. (2002) mapped WSR-88D radar coverages over the conterminous United States and pointed out the dearth of low-level coverage in the intermountain West. Uncertainty in rain rates are expected to increase when reflectivity is measured at higher altitudes and extrapolated to represent surface values, even when reflectivity was corrected using a modeled vertical profile of reflec- tivity. Thus, one of the objectives of HMT was to evaluate the improvement in QPE offered by research radars situated in mountainous terrain where WSR-88D beam blockages are common. Beam heights of the hybrid scan (in meters above MSL) were computed for SR1 and DAX and are illustrated in Fig. 8.

Figure $8 \mathrm{a}$ shows that two of the rain gauges, located at Bear River at Rollins Reservoir (BRE) and Alta (ATA), were situated in blocked radials from SR1's perspective. The SR1_stitched QPE product replaced SR1_1234 rain rates with those estimated by HYDROX out to a maximum range of $38 \mathrm{~km}$. The HYDROX radar provided better coverage over several gauges in the lower part of the basin, which helped to explain the improvement realized with the SR1_stitched product over SR1_1234. In addition, HYDROX is an X-band radar with polarimetric capabilities, which provided a mechanism to account for attenuation losses. We also computed rainfall accumulations for GAG_0, DAX_23, and SR1_stitched for all IOPs combined (Fig. 9). Subjective comparison of the accumulations in Fig. 9 indicates the DAX_23 and GAG_0 products captured the increasing gradient of precipitation in the upper parts of the basin that reach a maximum and then decrease at the crests. There appears to be a bias between the gauge analysis field and the DAX_23 product. The SR1_stitched product, on the other hand, illustrates qualitative agreement with the GAG_0 analysis but only in regions where there were no blocked radials from SR1's perspective.

To quantify the effect of radar coverage on QPE skill, the normalized bias has been computed in Fig. 10 as a function of radar sampling height in meters above MSL over each rain gauge location for all IOPs combined. Figures $10 \mathrm{a}-\mathrm{c}$ show the normalized bias is particularly dependent on radar sampling height. In comparing Figs. $10 \mathrm{c}, \mathrm{d}$, it is apparent that the VPR corrections reduced the overestimation that was present from $3.5-6.5 \mathrm{~km}$ in Fig. 10c and improved the underestimation problem above $6.5 \mathrm{~km}$. Further improvements are noted in the vertical error structure following the inclusion of HYDROX data in the QPE product (Fig. 10f). The most significant improvements occurred at sampling heights of 1.1 and $4.5 \mathrm{~km}$; the gauges at these locations were FHL and ATA, respectively. Figure 8a shows ATA was situated directly in a blocked radial from SR1, which apparently degraded the performance of the QPE value there. FHL was within $1 \mathrm{~km}$ distance from the SR1 site, which placed it within the near field of the radar and also subjected it to ground clutter removal procedures. Replacing the SR1 rainfall estimates with those measured from HYDROX in regions within the near field of the antenna led to a better QPE product over the FHL gauge site. 

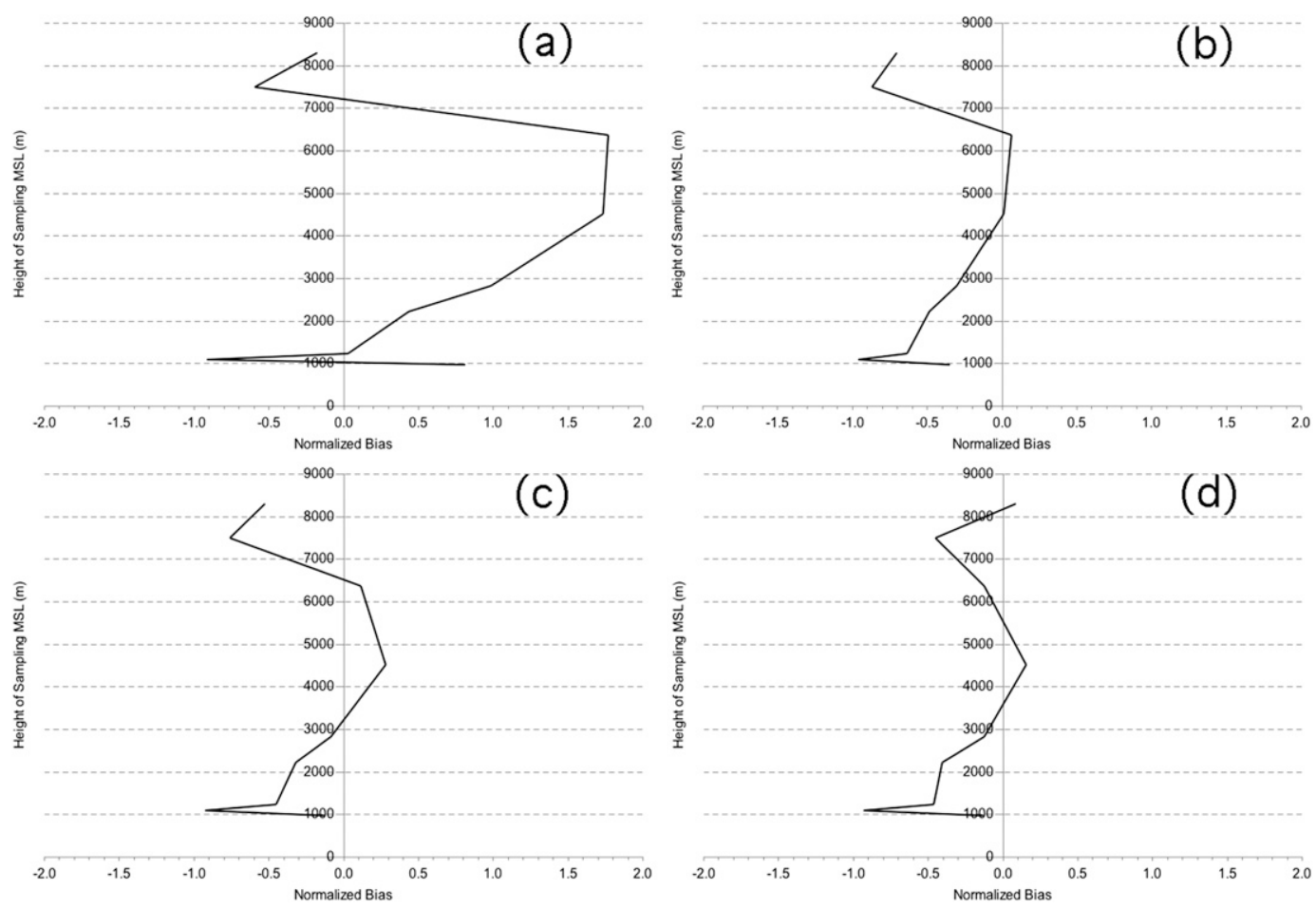

FIG. 10. Same as Fig. 7 but for normalized bias plotted as a function of radar sampling height in meters above MSL at each gauge site for (a) SR1_0, (b) SR1_1, (c) SR1_12, (d) SR1_123, (e) SR1_1234, (f) SR1_stitched, (g) DAX_0, and (h) DAX_23 QPE products.

Comparison of Figs. 10g,h shows the application of an optimized $Z-R$ relation found with disdrometer data, and a VPR correction method that was developed on SR1 data resulted in a skillful, but negatively biased, QPE product from the operational DAX radar. In fact, the normalized bias has less dependence on height than compared to the final QPE product from the research radars (see Figs. 10f,h). This finding indicates the procedures developed on the research radars apply directly to a NEXRAD situated as far as $147 \mathrm{~km}$ away. Moreover, the most skillful QPE product coming from the DAX radar is explained by the superior coverage the NEXRAD provides over the upper parts of the basin. The terrain generally rises from west to east along with the radar beams from DAX. Most importantly, there are no nearby trees or obstructions to block the DAX visibility over the ARB, which was certainly the case with the SR1 radar siting. This finding indicates careful consideration of nearby blockages due to terrain and trees must be taken when siting a research radar that is intended to be used as a gap-filling radar.

\section{Summary and conclusions}

The North Fork of the American River Basin (ARB) in California was heavily instrumented with in situ and remote sensing instruments during NOAA's Hydrometeorological Testbed experiment beginning in the winter of 2005/06. A network of 16 rain gauges, an X-band polarimetric radar (HYDROX), a C-band radar (SR1), an S-band NEXRAD radar at Sacramento (DAX), and a disdrometer were used in this study to quantify the skill in improvements to radar-based QPE products using hourly rain gauge accumulations as reference rainfall. The correction procedures have been applied in an iterative fashion to examine their effects on gap-filling, research radars having differing radar frequencies and polarization states. Moreover, the corrections have been adapted and applied to a nearby NEXRAD radar to determine the transferability of the methods to operational rainfall rate estimation algorithms.

The evaluation indicated calibration of radar reflectivity resulted in no significant improvements to rainfall fields, as computed using the default NEXRAD relation, compared to those derived from raw, uncorrected reflectivity data. However, after the parameters used to convert reflectivity data to rainfall rates were found with disdrometer measurements, better agreement with collocated rain gauge accumulations resulted. This result indicates that the effectiveness of radar calibration depends on simultaneous optimization of the $Z-R$ relation. Modest improvements to radar-based rainfall fields were 

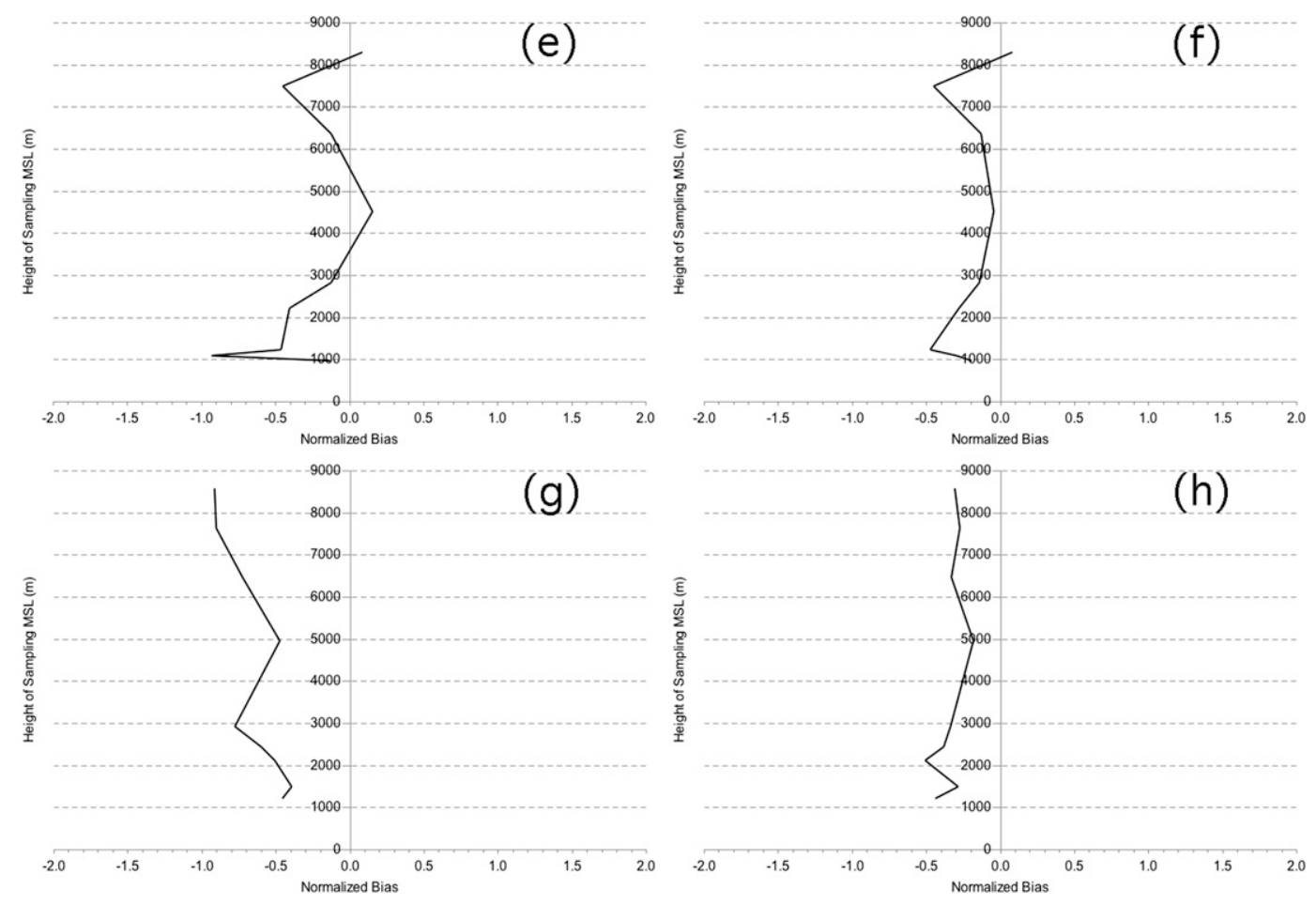

FIG. 10. (Continued)

realized through the application of a range-correction procedure using a modeled vertical profile of reflectivity and by using measurements from the HYDROX radar. In comparing all the QPE products, the lowest RMSE of $2.63 \mathrm{~mm}$ and highest Pearson correlation coefficient of 0.52 was achieved with data measured by the NEXRAD located near Sacramento, CA, with corrections that accounted for the variability of reflectivity with height and used optimized parameters in the $Z-R$ relation. SR1_stitched, which had a normalized bias of -0.18 , indicating $18 \%$ underestimation, an RMSE of $2.92 \mathrm{~mm}$ (with the bias removed), and a Pearson correlation coefficient of 0.47 , provided an improvement over the DAX_23 product in terms of the bias $(-0.18$ versus -0.32 ) but did not provide improvements in terms of the RMSE or the correlation (2.92 versus $2.62 \mathrm{~mm}$ and 0.47 versus 0.52 , respectively). First, this result demonstrated the transferability of QPE correction methods developed in complex terrain for research radars to an operational NEXRAD. These results prompted us to examine the operational versus experimental radar coverages over the ARB. SR1 had several blocked radials by nearby trees creating a "spoked" appearance in QPE fields. The blockages were mitigated in the lower part of the basin by replacing QPE values with those measured by the HYDROX radar. However, the maximum range of HYDROX was $38 \mathrm{~km}$, which meant QPE products from the merged, research radars relied exclusively on data from SR1 in the upper part of the basin. DAX had at least as good or even better coverage in these regions, even at a maximum distance of $147 \mathrm{~km}$ away, because it did not suffer from the tree blockage problems experienced by SR1. Plus, the terrain in the ARB generally increases in elevation from west to east in a similar manner that the DAX beam heights increase with range. It should be noted, however, that the low-level coverage offered by DAX is unusually good compared to typical radar coverages in the intermountain West, as seen in Maddox et al. (2002). Lastly, this study points out that careful consideration of radar sitings for gap-filling radars in study basins must be taken to avoid blockages due to nearby terrain, structures, and trees.

Acknowledgments. The authors have benefitted from many discussions about radar-based quantitative precipitation estimation techniques with Pedro Restrepo and David Kitzmiller (NOAA/NWS/OHD), Brooks Martner and David Kingsmill (CIRES, University of Colorado and NOAA/ESRL/PSD), and Marty Ralph (NOAA/ESRL/PSD). Much of the deployment costs for the SR1 participation in the Hydrometeorological Testbed experiment were provided by NOAA/OAR. The authors also would like to thank NOAA/ESRL/PSD and NOAA/NWS/OHD for providing internal reviews of 
this manuscript. Comments from three anonymous reviewers helped to improve the clarity and analysis procedures used in this manuscript.

\section{REFERENCES}

Akima, H., 1978: A method for bivariate interpolation and smooth surface fitting for irregularly distributed data points. $A C M$ Trans. Math. Software, 4, 148-159.

Andrieu, H., and J. D. Creutin, 1995: Identification of vertical profiles of radar reflectivities for hydrological applications using an inverse method. Part I: Formulation. J. Appl. Meteor., 34, 225-239.

Atlas, D., 2002: Radar calibration: Some simple approaches. Bull. Amer. Meteor. Soc., 83, 1313-1316.

Austin, P. M., 1987: Relation between measured radar reflectivity and surface rainfall. Mon. Wea. Rev., 115, 1053-1070.

—, and A. Bemis, 1950: A quantitative study of the "bright band" in radar precipitation echoes. J. Meteor., 7, 145-151.

Battan, L. J., 1976: Vertical air motions and the $Z-R$ relation. J. Appl. Meteor., 15, 1120-1121.

Bellon, A., G. Lee, and I. Zawadzki, 2005: Error statistics of VPR corrections in stratiform precipitation. J. Appl. Meteor., 44, 998-1015.

Biggerstaff, M. I., and Coauthors, 2005: The Shared Mobile Atmospheric Research and Teaching radar: A collaboration to enhance research and teaching. Bull. Amer. Meteor. Soc., 86, 1263-1274.

Ciach, G. J., 2003: Local random errors in tipping-bucket rain gauge measurements. J. Atmos. Oceanic Technol., 20, 752-759.

Dotzek, N., and T. Fehr, 2003: Relation between precipitation rates at the ground and aloft-A modeling study.J. Appl. Meteor., 42, 1285-1301.

Droegemeier, K. K., and Coauthors, 2000: Hydrological aspects of weather prediction and flood warnings: Report on the ninth prospectus development team of the U.S. Weather Research Program. Bull. Amer. Meteor. Soc., 81, 2665-2680.

Germann, U., and J. Joss, 2002: Mesobeta profiles to extrapolate radar precipitation measurements above the Alps to the ground level. J. Appl. Meteor., 41, 542-557.

Joss, J., and A. Waldvogel, 1990: Precipitation measurements and hydrology. Radar in Meteorology, D. Atlas, Ed., Amer. Meteor. Soc., 577-606.

— sons to operational precipitation profile corrections. J. Appl. Meteor., 34, 2612-2630.

— - J. C. Thams, and A. Waldvogel, 1968: The accuracy of daily rainfall measurements by radar. Proc. 13th Radar Meteorology Conf., Montreal, QC, Canada, Amer. Meteor. Soc., 448-451.

Kitchen, M., and P. M. Jackson, 1993: Weather radar performance at long range-Simulated and observed. J. Appl. Meteor., 32, 975-985.
, R. Brown, and A. G. Davies, 1994: Real-time correction of weather radar data for the effects of bright band, range and orographic growth in widespread precipitation. Quart. J. Roy. Meteor. Soc., 120, 1231-1254.

Legates, D. R., and T. L. DeLiberty, 1993: Precipitation measurement biases in the United States. Water Resour. Bull., 29, 855-861.

Maddox, R. A., J. Zhang, J. J. Gourley, and K. W. Howard, 2002: Weather radar coverage over the contiguous United States. Wea. Forecasting, 17, 927-934.

Marselek, J., 1981: Calibration of the tipping-bucket raingage. J. Hydrol., 53, 343-354.

Martner, B. E., K. A. Clark, S. Y. Matrosov, W. C. Campbell, and J. S. Gibson, 2001: NOAA/ETL's polarization-upgraded X-band "hydro" radar. Preprints, 30th Int. Conf. on Radar Meteorology, Munich, Germany, Amer. Meteor. Soc., P3.5. [Available online at http://ams.confex.com/ams/pdfpapers/21364.pdf.]

- S. E. Yuter, A. B. White, S. Y. Matrosov, D. E. Kingsmill, and F. M. Ralph, 2008: Raindrop size distributions and rain characteristics in California coastal rainfall for periods with and without a radar bright band. J. Hydrometeor., 9, 408-425.

Matrosov, S. Y., 2008: Assessment of radar signal attenuation caused by melting hydrometeor layer. IEEE Trans. Geosci. Remote Sens., 46, 1039-1047.

_ , D. E. Kingsmill, B. E. Martner, and F. M. Ralph, 2005: The utility of X-band polarimetric radar for quantitative estimates of rainfall parameter. J. Hydrometeor., 6, 248-262.

_ - K. A. Clark, and D. E. Kingsmill, 2007: A polarimetric radar approach to identify rain, melting-layer, and snow regions for applying corrections to vertical profiles of reflectivity. J. Appl. Meteor. Climatol., 46, 154-166.

Nystuen, J. A., 1999: Relative performance of automatic rain gauges under different rainfall conditions. J. Atmos. Oceanic Technol., 16, 1025-1043.

Ryzhkov, A. V., S. E. Giangrande, V. M. Melnikov, and T. J. Schuur, 2005: Calibration issues of dual-polarization radar measurements. J. Atmos. Oceanic Technol., 22, 1138-1155.

Seo, D.-J., J. P. Breidenbach, R. Fulton, D. Miller, and T. O'Bannon, 2000: Real-time adjustment of range-dependent biases in WSR-88D rainfall estimates due to nonuniform vertical profile of reflectivity. J. Hydrometeor., 1, 222-240.

Sibson, R., 1981: A brief description of natural neighbor interpolation. Interpreting Multivariate Data, V. Barnett, Ed., Wiley, 21-36.

Smith, C. J., 1986: The reduction of errors caused by bright bands in quantitative rainfall measurements made using radar. J. Atmos. Oceanic Technol., 3, 129-141.

Vignal, B., H. Andrieu, and J. D. Creutin, 1999: Identification of vertical profiles of reflectivity from volume scan radar data. J. Appl. Meteor., 38, 1214-1228.

Wilson, J., and E. Brandes, 1979: Radar measurement of rainfall-A summary. Bull. Amer. Meteor. Soc., 60, 1048-1058.

Zawadzki, I. I., 1975: On radar-raingauge comparison. J. Appl. Meteor., 14, 1430-1436. 